\title{
Cytomegalovirus Infection Is a Risk Factor in Gastrointestinal Cancer: A Cross-Sectional and Meta-Analysis Study
}

\author{
Ya-li Lv Fei-fei Han Zhuo-ling An Yangjie Jia Ling-ling Xuan Li-li Gong \\ Wen Zhang Lu-lu Ren Song Yang He Liu Li-hong Liu \\ Beijing Chao-Yang Hospital, Capital Medical University, Beijing, PR China
}

\section{Keywords \\ Cytomegalovirus · Infection - Gastrointestinal cancer · \\ Colorectal cancer · Gastric cancer · Meta-analysis}

\begin{abstract}
Background: This study was planned to investigate the association between human cytomegalovirus (HCMV) infection and gastrointestinal cancer (GIC) risk, by undertaking a meta-analysis and case-control cross-sectional study. Summary: A cross-sectional study analysis of $160 \mathrm{GIC}$ patients and 100 control subjects indicated significantly higher HCMV prevalence in GIC patients based on the HCMV IgM test. However, a similar analysis based on an lgG test revealed no significant relationship. Further meta-analysis of 11 studies, including 1,044 patients and 991 healthy subjects, displayed HCMV infection as an important risk factor for not only colorectal cancer occurrence and development based on a HCMV DNA test, but also for GIC based on a HCMV IgM test. However, the IgG test again displayed no significant relationship between HCMV infection and GIC occurrence. Key Message: Overall, our study revealed that HCMV infection is associated with an increased GIC risk. However, additional studies are warranted to elucidate the molecular mechanism underlying this association.

(c) 2020 S. Karger AG, Basel
\end{abstract}

\section{Introduction}

Gastric cancer (GC) and colorectal cancer (CRC) are the most common gastrointestinal cancers (GIC), and, according to World Health Organization (WHO) statistics, approximately 875,000 and $1,000,000$ new cases are diagnosed annually, worldwide $[1,2]$. Despite little information about their pathogenesis, it is clear that both are multifactorial diseases, and various factors including infectious agents have been observed to be involved in their genesis. More specifically, infectious agents like human papillomavirus, Helicobacter pylori, Epstein-Barr virus, and cytomegalovirus have commonly been implicated as causative agents for CRC and GC [3-5].

Among the various infectious microorganisms, human cytomegalovirus (HCMV) prevalence is wide in human populations. HCMV has been observed to survive in the host, after initial infection for long periods [6]. Based on one study, it appears that about $70-100 \%$ of the adults are infected with HCMV in the overall population worldwide [7]. Its infection is typically asymptomatic in healthy individuals [8] but immunologically immature and immunocompromised patients display severe symptoms [9]. HCMV belongs to the betaherpesvirinae subfamily, and its virion structure, viral gene expression kinetics, karger@karger.com

www.karger.com/int

(C) 2020 S. Karger AG, Base

Karger!
He Liu or Li-hong Liu

Beijing Chao-Yang Hospital, Capital Medical University

No. 8 Gongti South Road

Beijing 100020 (PR China)

liuheliuhe@126.com or lvyali_happy@163.com 
Table 1. Study participant characteristics

\begin{tabular}{lccc}
\hline Characteristic & $\begin{array}{l}\text { Patients with GIC } \\
(n=160)\end{array}$ & $\begin{array}{l}\text { Controls } \\
(n=100)\end{array}$ & $p$ value \\
\hline Age (mean \pm SD), years & $62.15 \pm 11.71$ & $62.82 \pm 10.41$ & 0.717 \\
Male sex, $n(\%)$ & $90(56.25)$ & $57(57)$ & 0.683 \\
Ethnicity, $n(\%)$ & & & 0.859 \\
$\quad$ Han & $158(98.75)$ & $99(99)$ & ns \\
$\quad$ Manchu & $2(1.25)$ & $1(1)$ & 0.119 \\
BMI (mean \pm SD) & $37(23.13)$ & $15(15)$ & 0.174 \\
Smoking, $n(\%)$ & $28(17.5)$ & $11(11)$ & 0.160 \\
Drinking, $n(\%)$ & & $25(25)$ & 0.176 \\
HCMV detection, $n(\%)$ & $53(33.13)$ & $18(18)$ & 0.008 \\
$\quad$ Serum HCMV IgG+ & $53(33.13)$ & & \\
$\quad$ Serum HCMV IgM+ & & & \\
\hline
\end{tabular}

and lifetime persistence in its host are very similar to other herpesvirus family members [9]. More recent studies have focused on HCMV associations with various cancers, including glioblastoma, breast cancer, CRC, and GC [10-12]. Additionally, HCMV has also been observed to induce gastrointestinal track disorders, like inflammatory bowel disease, ulceration, cell wall erosion, and mucosal hemorrhage [13, 14].

There have been conflicting reports about HCMV associations with GIC, and, thus, herein we have investigated HCMV prevalence in GIC patients in comparison to healthy subjects by undertaking a cross-sectional analysis, along with a comprehensive meta-analysis. The study was undertaken with the intent to explore the possible role of HCMV in GIC tumorigenesis and identify new strategies for prevention and treatment.

\section{Materials and Methods}

Patient Recruitment for Cross-Sectional Study Analysis

A total of 160 serum samples were collected from GIC patients for serological analysis between January 2016 and December 2017. In addition, 100 age- and sex-matched control serum samples were also collected from healthy individuals to be used as controls (Table 1). All serum samples were stored at $-80^{\circ} \mathrm{C}$ until analysis. This study was approved by the Ethics Committee of the Beijing ChaoYang Hospital, Capital Medical University, China (2015-research-161)

\section{ELISA Assay for Serum Analysis}

The serum IgG and IgM antibodies against HCMV were assessed in serum samples using an ELISA kit, according to the manufacturer's instructions (Sigma-Aldrich, St. Louis, MO, USA). The blank negative and positive controls were included in the kit. The results were statistically analyzed using SPSS software version 22 (SPSS, Chicago, IL, USA). The categorical variables were com- pared by using $\chi^{2}$ and Fisher's exact tests, while continuous variables were assessed using a $t$ test for data with a normal distribution and a Mann-Whitney U test for data without a normal distribution. The $p$ value of less than 0.05 indicated a significant difference.

\section{Identification of Relevant Studies for Meta-Analysis}

All eligible studies were identified from PubMed and Embase databases until February 2019, using the following key terms: "human cytomegalovirus" and "gastric cancer" or "colorectal cancer." The articles published in both the English and Chinese literature were considered. After initial identification of the relevant studies, their cross-references were further scanned to identify additional studies to be included in our meta-analysis.

\section{Inclusion Criteria and Meta-Analysis}

The identified studies were included in the meta-analysis, if they met the following selection criteria: (1) studies evaluating the association between HCMV infection and GC; (2) studies evaluating the association of HCMV infection with CRC; (3) case-control or self-control studies; (4) studies having information about the HCMV infection rate (numbers or percentage) for both patients and controls. All the conference abstracts, case reports, editorials, review articles, and letters were excluded.

The data extraction was primarily performed by two authors (Ya-li Lv and Yang-jie Jia). The study was included in our analysis only when both the authors reached consensus on its eligibility. When two authors disagreed, the two authors would rematch the original data with a third person overseeing until a consensus wass reached. The following information was extracted from each study: first author's surname, publication year, source of all patient cases, HCMV detection method, total numbers of cases and controls, and HCMV infection positivity rate both in cases and controls. The articles reporting the HCMV prevalence rate based on both enzyme-linked immunosorbent (ELISA) and polymerase chain reaction detection-based methods were included in the analysis.

The statistical analyses of the extracted data were performed using Review Manager (Review Manager 5.0 software) and Stata/ MP 11.0 software. The heterogeneity across the included studies was assessed using Cochran's w2 and inconsistency index $\left(I^{2}\right)$ tests. All the analyses were performed using a random-effects model and 
Table 2. Main characteristics of the studies included in the meta-analysis

\begin{tabular}{|c|c|c|c|c|c|c|c|c|c|}
\hline \multirow[t]{2}{*}{ First author } & \multirow{2}{*}{$\begin{array}{l}\text { Source } \\
\text { of cases }\end{array}$} & \multirow{2}{*}{$\begin{array}{l}\text { Study design } \\
\text { type }\end{array}$} & \multirow[t]{2}{*}{ Disease type } & \multirow{2}{*}{$\begin{array}{l}\text { Definition of } \\
\text { disease }\end{array}$} & \multirow{2}{*}{$\begin{array}{l}\text { Detection } \\
\text { of HCMV }\end{array}$} & \multicolumn{2}{|l|}{ Cases } & \multicolumn{2}{|l|}{ Controls } \\
\hline & & & & & & $\mathrm{HCMV}+$ & total & $\mathrm{HCMV}+$ & total \\
\hline Zhang [16], 2017 & China & $\begin{array}{l}\text { Case-control } \\
\text { Self-control }\end{array}$ & Gastric cancer & Histopathology & $\begin{array}{l}\operatorname{IgG} \\
\operatorname{IgM}\end{array}$ & $\begin{array}{r}76 \\
5\end{array}$ & 80 & $\begin{array}{r}78 \\
3\end{array}$ & 80 \\
\hline $\begin{array}{l}\text { Mehrabani-Khasraghi } \\
{[21], 2016}\end{array}$ & Iran & Case-control & Colorectal cancer & Histopathology & DNA & 8 & 15 & 13 & 35 \\
\hline Wang[17], 2000 & China & Case-control & Colorectal cancer & Histopathology & DNA & 6 & 8 & 0 & 3 \\
\hline Ye [20], 2016 & China & Case-control & Colorectal cancer & $\begin{array}{l}\text { Colonoscopy } \\
\text { Histopathology }\end{array}$ & $\begin{array}{l}\operatorname{IgG} \\
\operatorname{IgM}\end{array}$ & $\begin{array}{r}57 \\
3\end{array}$ & 60 & $\begin{array}{r}58 \\
1\end{array}$ & 60 \\
\hline Tang [18], 2007 & China & Case-control & Colorectal cancer & Histopathology & $\begin{array}{l}\operatorname{IgG} \\
\operatorname{IgM}\end{array}$ & $\begin{array}{l}96 \\
18\end{array}$ & 102 & $\begin{array}{r}83 \\
7\end{array}$ & 94 \\
\hline Chen [23], 2016 & China & Self-control & Colorectal cancer & Histopathology & DNA & 31 & 89 & 7 & 89 \\
\hline Tafvizi [19], 2014 & Iran & Self-control & Colorectal cancer & Histopathology & DNA & 15 & 50 & 5 & 50 \\
\hline Dimberg [22], 2013 & $\begin{array}{l}\text { Sweden } \\
\text { Vietnam }\end{array}$ & $\begin{array}{l}\text { Self-control } \\
\text { Self-control }\end{array}$ & Colorectal cancer & $\begin{array}{l}\text { Histopathology } \\
\text { Histopathology }\end{array}$ & $\begin{array}{l}\text { DNA } \\
\text { DNA }\end{array}$ & $\begin{array}{l}18 \\
33\end{array}$ & $\begin{array}{r}119 \\
83\end{array}$ & $\begin{array}{r}2 \\
10\end{array}$ & $\begin{array}{r}119 \\
83\end{array}$ \\
\hline Chen [11], 2012 & China & Self-control & Colorectal cancer & Histopathology & DNA & 69 & 163 & 14 & 163 \\
\hline Chen [4], 2015 & China & Self-control & Colorectal cancer & Histopathology & DNA & 49 & 115 & 13 & 115 \\
\hline $\begin{array}{l}\text { Lv [14], } 2018 \\
\text { (current study) }\end{array}$ & China & Self-control & $\begin{array}{l}\text { Gastric and colorectal } \\
\text { cancer }\end{array}$ & Histopathology & $\begin{array}{l}\operatorname{IgG} \\
\operatorname{IgM}\end{array}$ & $\begin{array}{l}53 \\
53\end{array}$ & $\begin{array}{l}160 \\
160\end{array}$ & $\begin{array}{l}25 \\
18\end{array}$ & $\begin{array}{l}100 \\
100\end{array}$ \\
\hline
\end{tabular}

OR (odds ratio), and their corresponding 95\% confidence intervals (CI) were estimated. The statistical significance of pooled ORs was determined using a $z$ test, and a $p$ value of less than 0.05 was considered significant. The statistical heterogeneity was compared using $\chi^{2}$ square and $I^{2}$ statistics, where a $I^{2}$ value of more than $50 \%$ reflected substantial heterogeneity [15].

\section{Results}

\section{GIC Patients' Characteristics}

In our cross-sectional study, we analyzed 160 GIC patients along with 100 age-, sex-, and ethnicity-matched control subjects for HCMV prevalence between the years 2016 and 2017. The mean age of GIC patients was 62.15 \pm 11.71 years, and 90 were male. In control subjects, the age and gender were comparable. In addition, the ethnicity and socioeconomic status of the two groups were also similar. The complete information about control and patient characteristics has been summarized in Table 1.

\section{Analysis of HCMV Prevalence among GIC Patients}

ELISA assay-based analysis revealed that HCMV prevalence was significantly higher among GIC patients in comparison to control subjects (OR 2.26 [95\% CI: 1.23-
4.14]), based on an IgM antibody test. Similarly, an IgG test also showed the same trend of a slightly higher HCMV prevalence in GIC patients (33.13\%) in comparison to the control subjects (25\%). However, the IgG test of HCMV prevalence between GIC patients (33.13\%) and the control subjects (25\%) showed no significance (OR 1.49 [95\% CI: 0.85-2.60]), as shown in Table 1.

\section{Meta-Analysis of HCMV Prevalence}

Based on the study selection criteria, we initially identified 296 potentially relevant studies from the electronic databases. Among these, 229 were excluded after reviewing the abstracts. The detailed evaluation of the 67 remaining studies resulted in the further exclusion of 57 due to duplicated publications, lack of adequate data, or no original date for the meta-analysis. Finally, 10 publications were included in our meta-analysis [11, 16-24]. The study selection process has been depicted as a flow chart in online supplementary Figure 1 (for all online suppl. material, see www.karger.com/doi/10.1159/000506683). In addition, we also included our cross-sectional analysis data about HCMV prevalence in 160 GIC patients and 100 control subjects as a separate study. Thus, overall, 11 studies including 1,044 patients and 991 control subjects were part of the final meta-analysis. Two different meth-
12

Intervirology 2020;63:10-16 DOI: $10.1159 / 000506683$
Lv/Han/An/Jia/Xuan/Gong/Zhang/Ren/ Yang/Liu/Liu 


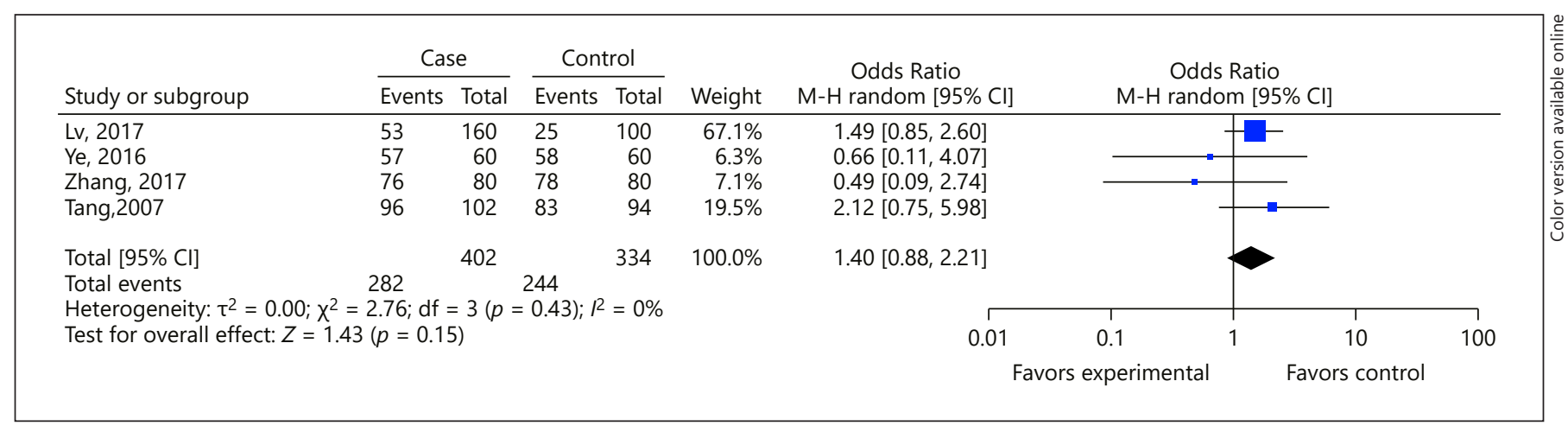

Fig. 1. Forest plot (using a random-effect model) analysis showing the association between GIC and HCMV infection, stratified using the HCMV IgG test.

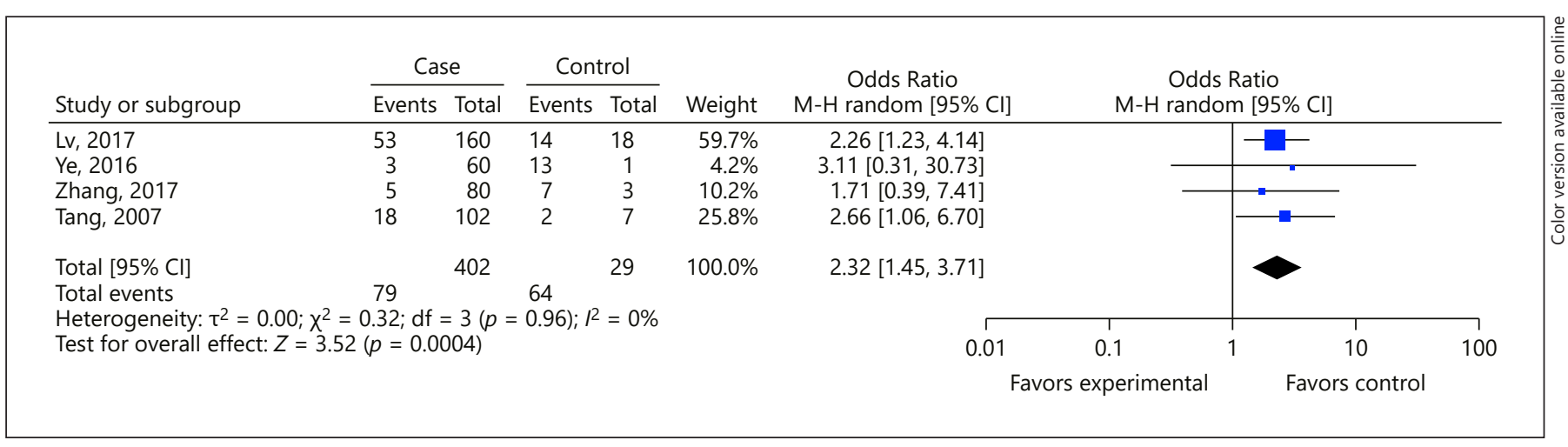

Fig. 2. Forest plot (using a random-effect model) analysis showing the association between GIC and HCMV infection, stratified based on the HCMV IgM test.

ods were used in these studies to detect the HCMV infection. A total of 4 studies used an ELISA assay to identify the HCMV infection, while another 7 studies used a more sensitive polymerase chain reaction-based assay. Also, 10 studies included an Asian population, while 1 study analyzed patients from two different regions (Sweden and Vietnam). All 11 studies were case-control studies. The complete characteristics of patients and control subjects have been summarized in Table 2 .

Meta-analysis of the 11 studies revealed that an HCMV association, based on IgG tests, was evident in $70.15 \%$ of the GIC patients (282/402) and 73.05\% of the control subjects $(244 / 334)$, as shown in Figure 1. In parallel, IgM tests demonstrated HCMV association in $19.65 \%$ of the GIC patients (79/402) and $8.68 \%$ of the control subjects (29/334; Fig. 2). Furthermore, a DNA test revealed an HCMV association in $35.66 \%$ of the GIC patients (229/ 642 ) and $9.74 \%$ of the control subjects (64/657; Fig. 3). Therefore, 2 out of 3 tests demonstrated that exposure to an HCMV infection increased the risk for GIC, as an
IgM test revealed an OR of 2.32 (95\% CI: 1.45-3.71; Fig. 2), while a DNA test showed an OR of 5.72 (95\% CI: 4.14-7.91; Fig. 3).

\section{Sensitivity Analysis}

In addition, we also performed a sensitivity analysis to examine the stability of our results. After exclusion of one study at a time, our meta-analyses showed no significant changes in the overall OR values, as shown in Table 3. This indicated that no single particular study significantly affected the final OR values, and, therefore, our data appeared to be stable and reliable.

\section{Publication Bias}

Next, we also conducted a publication bias analysis of the included studies using a Begg's funnel plot and Egger's test. Our data indicated no evidence of publication bias, as seen in online supplementary Figure 2. The funnel plot showed some dissymmetry, but Egger's test provided no statistical evidence of funnel plot asymmetry. 


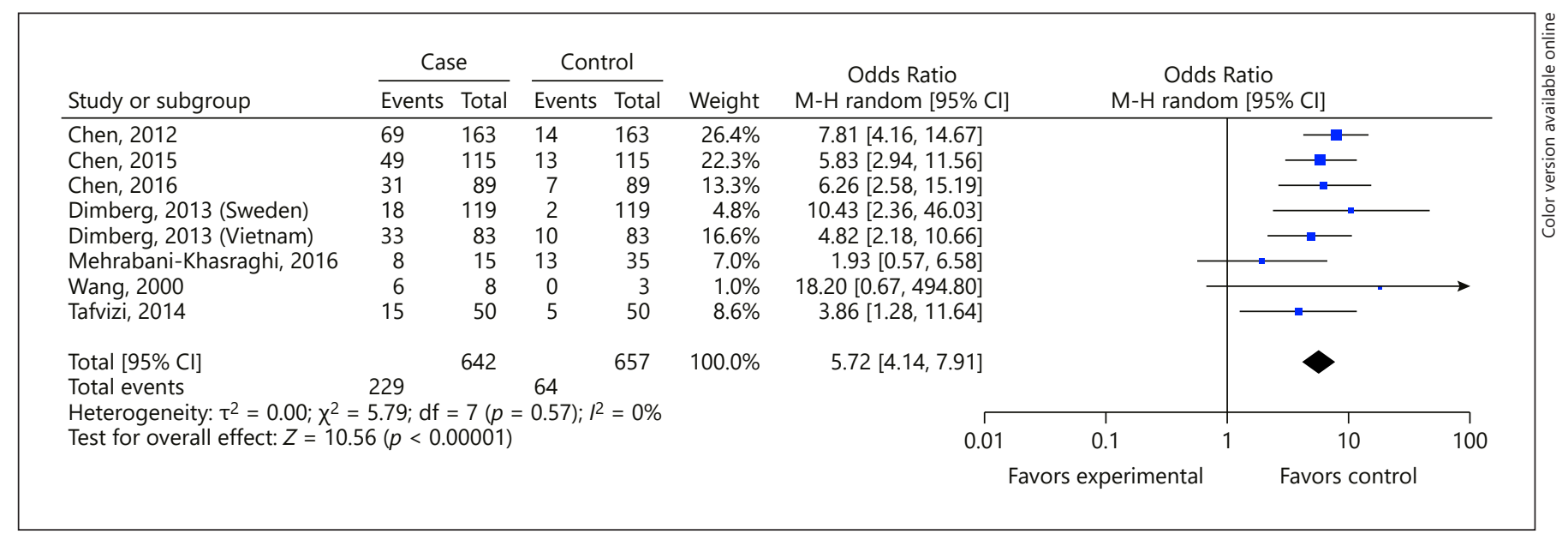

Fig. 3. Forest plot (using random-effect model) analysis showing the association between GIC and HCMV infection, stratified based on the HCMV DNA test.

Table 3. Sensitivity analysis

\begin{tabular}{llll}
\hline Study excluded & OR & $95 \%$ CI & $p$ \\
\hline IgG tests & & & \\
None & 1.40 & $0.88-2.21$ & 0.15 \\
Lv [14], 2017 & 1.12 & $0.43-2.93$ & 0.82 \\
Ye [20], 2016 & 1.47 & $0.90-2.40$ & 0.12 \\
Zhang [16], 2017 & 1.51 & $0.94-2.44$ & 0.09 \\
Tang [18], 2007 & 1.26 & $0.76-2.11$ & 0.37 \\
\hline IgM tests & & & \\
None & 2.32 & $1.45-3.71$ & 0.0004 \\
Lv [14], 2017 & 2.42 & $1.15-5.07$ & 0.02 \\
Ye [20], 2016 & 2.29 & $1.42-3.70$ & 0.0007 \\
Zhang [16], 2017 & 2.40 & $1.46-3.94$ & 0.0005 \\
Tang [18], 2007 & 2.21 & $1.28-3.81$ & 0.004 \\
\hline DNA tests & & & \\
None & 5.72 & $4.14-7.91$ & $<0.00001$ \\
Chen [11], 2012 & 5.11 & $3.51-7.46$ & $<0.00001$ \\
Chen [4], 2015 & 5.69 & $3.94-8.21$ & $<0.00001$ \\
Chen [23], 2016 & 5.64 & $3.98-7.99$ & $<0.00001$ \\
Dimberg [22], 2013 (Sweden) & 5.55 & $3.98-7.73$ & $<0.00001$ \\
Dimberg [22], 2013 (Vietnam) & 5.92 & $4.15-8.44$ & $<0.00001$ \\
Mehrabani-Khasraghi [21], 2016 & 6.21 & $4.44-8.68$ & $<0.00001$ \\
Wang [17], 2000 & 5.66 & $4.09-7.83$ & $<0.00001$ \\
Tafvizi [19], 2014 & 5.94 & $4.23-8.33$ & $<0.00001$ \\
\hline & & & \\
\hline
\end{tabular}

\section{Discussion}

The GIC (including GC and CRC) seems to be linked with the second and third highest mortality rates, respectively, among all cancers and, thus, pose an enormous threat to public health $[25,26]$. A high mortality rate and metastasis risk highlights that early detection of their pathogenesis is crucial for patients [27]. Historically, the relationship between HCMV and CRC was first noticed in the year 1978 [28], and, since then, this topic has attracted much attention from the scientific community, including clinicians. However, the exact role of the HCMV infection in GIC patients has still not been deciphered, despite multiple efforts. Moreover, there have been conflicting reports in the literature about an HCMV association with GIC. Therefore, we, in our current study, first performed a cross-sectional analysis to detect the association and prevalence of an HCMV infection among GIC patients and healthy control subjects, using ELISA-based IgG and IgM antibody analyses. In addition, we also undertook a comprehensive meta-analysis by identifying relevant studies from the literature, to clearly understand the association between an HCMV infection and GIC.

Our data from the cross-sectional study revealed that HCMV detection was significantly higher among GIC patients compared to control subjects, based on an IgM test. However, an IgG test displayed no significant relationship between GIC patients and control subjects. The reasons may be that DNA and IgM are respectively used as indicators of virus replication, proliferation, and shortterm infection, while IgG is used as indicator of long-term infection. However, as a latent virus, HCMV might not consistently express products during the whole period of infection, which would cause false-negative results on an $\operatorname{IgG}$ test $[29,30]$. This observation was consistent with the results observed in other studies included in our metaanalysis, where multiple serological and histological stud- 
ies demonstrating that an HCMV infection is a distinct risk factor for CRC occurrence and development based on HCMV DNA tests and for GIC based on IgM tests. Importantly, some studies showed no significant relationship between an HCMV infection and GIC occurrence because they typically analyzed viral proteins, like IE, US28, and pp65 [12, 31]. These studies were however small and were not included in our own meta-analysis.

Therefore, despite variable HCMV detection rates using different methods, it is clear that its prevalence is significantly higher in tumor serum and tissue samples than the paired normal controls, based on IgM and DNA tests. On average, we suspect that HCMV infections might be 2-5 times higher in GIC patients than in control subjects, thereby pointing towards a strong association between GIC and HCMV. Consistent with our data, two independent studies $[12,28]$ also suggested HCMV infection is an important risk factor for CRC and GC. However, 2 other studies were not able to confirm this association $[32,33]$. The controversy about an HCMV association with GIC can be attributed to the methodology used to detect the virus and the analysis of variable protein markers. This warrants the use of more powerful techniques along with larger statistical populations in future studies to further resolve this issue of HCMV infection and GIC.

Typically, GIC is a multifactorial disease, and its occurrence and development are regulated by multiple factors including microbial infection, genetic predisposition, and environmental factors [34-36]. Some studies have indicated that viral modification of the host epigenome can play an important role in GIC initiation and progression [37]. However, some other studies have demonstrated that cytokine gene polymorphism can regulate HCMV reactivation in cancer patients [38]. Specifically, it has been proposed that HCMV may increase and reinforce cancerous cell malignant properties by activating the cell survival and growth signaling pathway [39]. In addition, it has also been hypothesized that the virus is carried to the neoplasm by myeloid cells and later indwelled at the malignant mucosal epithelium [11]. Another study [40] has reported that proteins displayed on HCMV prevent host immune system cells from identifying and eliminating this virus and, thereby, facilitating long-time infection, which subsequently leads to tumor progression. However, the exact molecular mechanism underlying HCMV association with GIC has still not been elucidated, and additional studies would be required to understand this complex relationship.

It is equally important to highlight the limitations of our study. First, in the cross-sectional study analysis, we only used an ELISA method to detect HCMV infection in the serum. Second, we only focused on detecting HCMV IgG and IgM levels in our cross-sectional analysis study, and the studies included for meta-analysis also only focused on IgG and IgM, along with a DNA-based detection method. The data based on detection of other viral proteins was not considered. Third, our meta-analysis was only based on 11 studies due to strict inclusion criteria, which appears to be small, and, thus, additional large cohort studies would be helpful to analyze the association.

\section{Conclusions}

In conclusion, based on our data, an HCMV infection appeared to be significantly associated with an increased risk of GIC. However, additional studies using a larger sample size would be helpful to further establish this association and also help to understand the molecular mechanism underlying it.

\section{Acknowledgments}

Thanks are due to Zirui Wan for drafting this manuscript and critically revising it for important intellectual content.

\section{Statement of Ethics}

This study was approved by the Ethics Committee of the Beijing Chao-Yang Hospital, Capital Medical University, China (2015-research-161). Written informed consent was obtained from all individual participants included in the study.

\section{Disclosure Statement}

The authors declare that they have no conflict of interest.

\section{Funding Sources}

This study was supported by the Beijing Natural Science Foundation (grant No. 7151004) and the Natural Science Foundation of China (grant No. 81500336).

\section{Author Contributions}

Ya-li Lv, Yang-jie Jia and Fei-fei Han extracted data and reached a consensus on all of the eligibility items according to the inclusion criteria listed above. Ya-li Lv participated in the sequence alignment and drafted the manuscript. Zhuo-ling An, Ling-ling Xuan, Li-li Gong, Wen Zhang, Lu-lu Ren, and Song Yang participated in the design of the study and performed the statistical analysis. Lihong Liu and Liu He conceived the study, participated in its design and coordination, along with helping to draft the manuscript. All authors read and approved the final paper. 


\section{References}

1 Jemal A, Bray F, Center MM, Ferlay J, Ward E, Forman D. Global cancer statistics. CA Cancer J Clin. 2011 Mar-Apr;61(2):69-90.

2 Ferlay J, Shin HR, Bray F, Forman D, Mathers C, Parkin DM. Estimates of worldwide burden of cancer in 2008: Globocan 2008. Int J Cancer. 2010 Dec;127(12):2893-917.

3 Collins D, Hogan AM, Winter DC. Microbial and viral pathogens in colorectal cancer. Lancet Oncol. 2011 May;12(5):504-12.

4 Chen XZ, Chen H, Castro FA, Hu JK, Brenner $\mathrm{H}$. Epstein-Barr virus infection and gastric cancer: a systematic review. Medicine (Baltimore). 2015 May;94(20):e792.

5 Camargo MC, Kim KM, Matsuo K, Torres J, Liao LM, Morgan DR, et al. Anti-helicobacter pylori antibody profiles in epstein-barr virus (ebv)-positive and ebv-negative gastric cancer. Helicobacter. 2016 Apr;21(2):153-7.

6 Favacho AR, Cintra EA, Coelho LC, Linhares MI. In vitro activity evaluation of Parkia pendula seed lectin against human cytomegalovirus and herpes virus 6. Biologicals. 2007 Jun; 35(3):189-94.

7 Söderberg-Nauclér C. HCMV microinfections in inflammatory diseases and cancer. J Clin Virol. 2008 Mar;41(3):218-23.

8 Sissons JG, Carmichael AJ. Clinical aspects and management of cytomegalovirus infection. J Infect. 2002 Feb;44(2):78-83.

9 Landolfo S, Gariglio M, Gribaudo G, Lembo D. The human cytomegalovirus. Pharmacol Ther. 2003 Jun;98(3):269-97.

10 Bishop RK, Valle Oseguera CA, Spencer JV. Human Cytomegalovirus interleukin-10 promotes proliferation and migration of MCF-7 breast cancer cells. Cancer Cell Microenviron. 2015;2(1):2.

11 Chen HP, Jiang JK, Chen CY, Chou TY, Chen YC, Chang YT, et al. Human cytomegalovirus preferentially infects the neoplastic epithelium of colorectal cancer: a quantitative and histological analysis. J Clin Virol. 2012 Jul; 54(3):240-4.

12 Harkins L, Volk AL, Samanta M, Mikolaenko I, Britt WJ, Bland KI, et al. Specific localisation of human cytomegalovirus nucleic acids and proteins in human colorectal cancer. Lancet. 2002 Nov;360(9345):1557-63.

13 Goodgame RW. Gastrointestinal cytomegalovirus disease. Ann Intern Med. 1993 Nov; 119(9):924-35.

14 Lv YL, Han FF, Jia YJ, Wan ZR, Gong LL, Liu $\mathrm{H}$, et al. Is cytomegalovirus infection related to inflammatory bowel disease, especially steroid-resistant inflammatory bowel disease? A meta-analysis. Infect Drug Resist. 2017 Dec; 10:511-9.

15 Higgins JP, Thompson SG, Deeks JJ, Altman DG. Measuring inconsistency in meta-analyses. BMJ. 2003 Sep;327(7414):557-60.
16 Zhang L, Guo G, Xu J, Sun X, Chen W, Jin J, et al. Human cytomegalovirus detection in gastric cancer and its possible association with lymphatic metastasis. Diagn Microbiol Infect Dis. 2017 May;88(1):62-8.

17 Wang NX, Jiang GY. Detection of CMV DNA in colorectal neoplasms. Chin J Clin Oncol. 2000;27:852-4.

18 Tang ZY, Li Q, Deng LF, Chen LH. Preliminary study of relationship between human cytomegalovirus infection and colon carcinoma. Pract Prev Med. 2007;14:688-90.

19 Tafvizi F, Fard ZT. Detection of human cytomegalovirus in patients with colorectal cancer by nested-PCR. Asian Pac J Cancer Prev. 2014;15(3):1453-7.

20 Meng-Si Ye YH, Yang SX, Lin H, Xue ZX, Cai ZZ. Clinical relevance between human cytomegalovirus infection and colorectal cancer. Shijie Huaren Xiaohua Zazhi. 2016;24:44-50. Chinese.

21 Mehrabani-Khasraghi S, Ameli M, Khalily F. Demonstration of herpes simplex virus, cytomegalovirus, and epstein-barr virus in colorectal cancer. Iran Biomed J. 2016 Nov; 20(5):302-6.

22 Dimberg J, Hong TT, Skarstedt M, Löfgren S, Zar N, Matussek A. Detection of cytomegalovirus DNA in colorectal tissue from Swedish and Vietnamese patients with colorectal cancer. Anticancer Res. 2013 Nov;33(11):494750.

23 Chen HP, Jiang JK, Chen CY, Yang CY, Chen $\mathrm{YC}$, Lin $\mathrm{CH}$, et al. Identification of human cytomegalovirus in tumour tissues of colorectal cancer and its association with the outcome of non-elderly patients. J Gen Virol. 2016 Sep; 97(9):2411-20.

24 Chen HP, Jiang JK, Chan CH, Teo WH, Yang $\mathrm{CY}$, Chen YC, et al. Genetic polymorphisms of the human cytomegalovirus UL144 gene in colorectal cancer and its association with clinical outcome. J Gen Virol. 2015 Dec;96(12): 3613-23.

25 Ferlay J, Soerjomataram I, Dikshit R, Eser S, Mathers C, Rebelo M, et al. Cancer incidence and mortality worldwide: sources, methods and major patterns in GLOBOCAN 2012. Int I Cancer. 2015 Mar;136(5):E359-86.

26 Sung JJ, Ng EK, Lin JT, Ho KY, Ji JF, Sugano $\mathrm{K}$, et al.; Asia Pacific GI Oncology Summit Group. Digestive cancer management in Asia: position statements: a report on GI Oncology Summit in 2011. J Gastroenterol Hepatol. 2012 Sep;27(9):1417-22.

27 Ouyang DL, Chen JJ, Getzenberg RH, Schoen RE. Noninvasive testing for colorectal cancer: a review. Am J Gastroenterol. 2005 Jun; 100(6):1393-403.

28 Huang ES, Roche JK. Cytomegalovirus D.N.A. and adenocarcinoma of the colon: evidence for latent viral infection. Lancet. 1978 May;1(8071):957-60.
29 Sandford GR, Schumacher U, Ettinger J, Brune W, Hayward GS, Burns WH, et al. Deletion of the rat cytomegalovirus immediateearly 1 gene results in a virus capable of establishing latency, but with lower levels of acute virus replication and latency that compromise reactivation efficiency. J Gen Virol. 2010 Mar;91(Pt 3):616-21.

30 Penkert RR, Kalejta RF. Nuclear localization of tegument-delivered pp71 in human cytomegalovirus-infected cells is facilitated by one or more factors present in terminally differentiated fibroblasts. J Virol. 2010 Oct;84(19): 9853-63

31 Cai ZZ, Xu JG, Zhou YH, Zheng JH, Lin KZ, Zheng SZ, et al. Human cytomegalovirus-encoded US28 may act as a tumor promoter in colorectal cancer. World J Gastroenterol. 2016 Mar;22(9):2789-98.

32 Bender C, Zipeto D, Bidoia C, Costantini S, Zamò A, Menestrina F, et al. Analysis of colorectal cancers for human cytomegalovirus presence. Infect Agent Cancer. 2009 Apr; 4(1):6.

33 Mariguela VC, Chacha SG, Cunha AA, Troncon LE, Zucoloto S, Figueiredo LT. Cytomegalovirus in colorectal cancer and idiopathic ulcerative colitis. Rev Inst Med Trop São Paulo. 2008 Mar-Apr;50(2):83-7.

34 Figueiredo C, Costa S, Karameris A, Machado JC. Pathogenesis of gastric cancer. Helicobacter. 2015 Sep;20 Suppl 1:30-5.

35 Hunt RH, Camilleri M, Crowe SE, El-Omar EM, Fox JG, Kuipers EJ, et al. The stomach in health and disease. Gut. 2015 Oct;64(10): 1650-68

36 Markowitz SD, Bertagnolli MM. Molecular origins of cancer: molecular basis of colorectal cancer. N Engl J Med. 2009 Dec;361(25): 2449-60.

37 Paschos K, Allday MJ. Epigenetic reprogramming of host genes in viral and microbial pathogenesis. Trends Microbiol. 2010 Oct; 18(10):439-47.

38 Cano P, Han FS, Wang HL, Fernandez-Vina M, Han XY. Cytokine gene polymorphisms affect reactivation of cytomegalovirus in $\mathrm{pa}$ tients with cancer. Cytokine. 2012 Nov;60(2): 417-22.

39 Bongers G, Maussang D, Muniz LR, Noriega VM, Fraile-Ramos A, Barker N, et al. The cytomegalovirus-encoded chemokine receptor US28 promotes intestinal neoplasia in transgenic mice. J Clin Invest. 2010 Nov;120(11): 3969-78.

40 Cinatl J Jr, Scholz M, Doerr HW. Role of tumor cell immune escape mechanisms in cytomegalovirus-mediated oncomodulation. Med Res Rev. 2005 Mar;25(2):167-85. 